\title{
Molecular Analysis of the Rice MAP Kinase Gene Family in Relation to Magnaporthe grisea Infection
}

\author{
Nathan S. Reyna and Yinong Yang \\ Department of Plant Pathology and Program in Cell and Molecular Biology, University of Arkansas, Fayetteville, AR 72701, \\ U.S.A.
}

Submitted 31 May 2005. Accepted 1 December 2005.

\begin{abstract}
Mitogen-activated protein kinase (MAPK) cascades play a crucial role in plant growth and development as well as biotic and abiotic stress responses. In Arabidopsis, 20 MAPKs have been identified and divided into four major groups. In rice, a monocot model and economically important cereal crop, only five MAPKs were characterized, including three related to the host defense response. In this study, we have identified 17 members of the rice MAPK gene $(O s M P K)$ family through an in silico search of rice genome databases. Based on the phylogenetic analysis and pairwise comparison of Arabidopsis and rice MAPKs, we propose that MAPKs can be divided into six groups. Interestingly, the rice genome contains many more MAPKs with the TDY phosphorylation site (11 members) than with the TEY motif (six members). In contrast, the Arabidopsis genome contains more MAPKs with the TEY motif (12 members) than with the TDY motif (eight members). Upon inoculation with the blast fungus (Magnaporthe grisea), nine of $17 O S M P K$ genes were found to be induced at the mRNA level during either early, late, or both stages of infection. Four of the $M$. grisea-induced $O S M P K$ genes were associated with host-cell death in the lesion-mimic rice mutant, and eight of them were differentially induced in response to defense signal molecules such as jasmonic acid, salicylic acid, abscisic acid, and ethylene. The genome-wide expression analysis suggests that about half of the rice MAPK genes are associated with pathogen infection and host defense response.
\end{abstract}

Additional keywords: defense signal transduction, Oryza sativa, rice blast fungus.

Mitogen-activated protein kinases (MAPKs) are involved in a plethora of signaling pathways associated with various abiotic and biotic stress responses (Hirt 1997; Jonak et al. 2002; Ligterink and Hirt 2001; Nakagami et al. 2005). Typically, the MAPK pathway consists of three interlinking proteins that form what is referred to as a MAPK cascade that conveys a perceived external signal to the nucleus. First, a MAPKKK phosphorylates a serine or threonine residue on a MAPKK, which in turn, activates a MAPK, the last protein in the cascade. MAPKs are activated by the dual phosphorylation of a threonine and tyrosine residue by the MAPKK. The acti-

Corresponding author: Y. Yang; 217 Plant Science Building; Telephone: +1.479.575.5635; Fax: +1.479.575.7601; E-mail: yiyang@uark.edu

Current address of N. S. Reyna: Department of Biological Sciences, Howard Payne University, Brownwood, TX 76801, U.S.A. vated MAPK leads to the phosphorylation of transcription factors and other signaling components that regulate the expression of downstream genes.

Increasing evidence has shown that many plant MAPKs are induced by pathogen infection and defense signaling molecules and are important components in defense signal transduction (Pedley and Martin 2005; Tena et al. 2001; Zhang and Klessig 2001). Yang and associates (2001) showed that the salicylic acid-inducible protein kinase (SIPK) and the wound-inducible protein kinase (WIPK), both from tobacco (Nicotiana tabacum), were induced by a fungal elicitor from a phytopathogenic Phytophthora spp. The NtMEK2 (a tobacco MAPKK)-mediated induction of both SIPK and WIPK in transgenic plants resulted in hypersensitive cell death and activation of defense genes. In transgenic tobacco plants expressing the tomato $C f-9$ resistance gene, both SIPK and WIPK were shown to be part of $C f-9 / A v r 9$ mediated resistance to Cladosporium fulvum (HammondKosack et al. 1998; Romeis et al. 1999). The WIPK gene was also shown to be induced by Tobacco mosaic virus (TMV) in tobacco plants carrying the $N$ resistance gene (Zhang et al. 1998).

During the past decade, tremendous progress has been made towards the functional understanding of all genes in the model dicot Arabidopsis. A total of 20 MAPKs have been identified from the Arabidopsis genome and are currently being analyzed using functional genomic approaches (Ichimura et al. 2002). However, little is known about the MAPK gene family and their function and regulation in rice (Oryza sativa) and other economically important cereal crops. Up to date, only five MAPKs (OsWJUMK1, Agrawal et al. 2003a; $O s M A P K 4$, Fu et al. 2002; OsBWMK1, He et al. 1999; Os$M A P K 6$, Lieberherr et al. 2005; OsMAPK5, Xiong and Yang 2003) have been characterized in rice. Of these five, three (OsBWMK1, OsMAPK5, and OsMAPK6) have been investigated as to how they relate to the plant defense response (He et al. 1999; Lieberherr et al. 2005; Song and Goodman et al. 2002; Xiong and Yang 2003). The BWMK1 (blast- and wound-induced MAP kinase 1) gene was induced within $4 \mathrm{~h}$ after inoculation with the rice blast fungus (Magnaporthe grisea) and $30 \mathrm{~min}$ after mechanical wounding (He et al. 1999). $B W M K 1$ was induced by both virulent and avirulent blast isolates as well as by an appressorium-deficient blast mutant. The induction of $B W M K 1$ by an appressorium-deficient blast mutant indicates that the activations of $B W M K 1$ by $M$. grisea and by wounding were likely mediated through different signal pathways (He et al. 1999). The OsMAPK5 gene (also known as OsMSRMK2, OsMAPK2, OsBIMK1, or OsMAP1) has been isolated by several research groups and shown to be inducible by various biotic and abiotic stresses (Agrawal et al. 2002; Huang et al. 2002; Song and Goodman 
2002; Wen et al. 2002; Xiong et al. 2001). Molecular, biochemical, and transgenic analyses demonstrated that $O s$ MAPK5 is a positive regulator of abiotic stress tolerance but acts as a negative regulator of rice disease resistance (Xiong and Yang 2003). Most recently, OsMAPK6 was reported to be posttranslationally activated by a sphingolipid elicitor and regulated by the small GTPase OsRac1 and heterotrimeric Gprotein in rice (Lieberherr et al. 2005)

In this study, we have conducted an in silico search of rice genome databases to further identify members of the rice MAPK gene family. A total of 17 rice MAPKs were identified and classified according to the naming system suggested by Ichimura and associates (2002). These 17 rice MAPKs have been anchored to specific chromosomes and grouped based on their phylogenetic relationship. Furthermore, quantitative reverse transcription-polymerase chain reaction (QRT-PCR) was used to examine the expression pattern of these 17 rice MAPK genes $(O S M P K \mathrm{~s})$ in response to the fungal infection and hostcell death as well as defense signaling molecules such as jasmonic acid (JA), salicylic acid (SA), abscisic acid (ABA), and ethylene (ET). The expression analysis reveals that about half of the rice MAPK genes are inducible at the mRNA level by pathogen infection, host-cell death, and defense signaling molecules, either singly or in combination.

\section{RESULTS}

\section{Genomic identification and phylogenetic analyses of the rice MAPK gene.}

Previous studies have identified and reported at least seven rice MAPKs (Arawal et al. 2003a; Ichimura et al. 2002). Five of them were characterized and shown to be associated with biotic or abiotic (or both) stress responses. Some of these MAPKs, such as OsMAPK5, have been reported by several different labs and thus have been given different names (OsMSRMK2, OsMAPK2, OsMAP1, or OsBIMK1). After extensive bioinformatic analysis of rice genome databases, a total of 17 OsMPKs were identified (Table 1). Our analysis of the majority of rice MAPKs has allowed us to adopt a less confusing nomenclature. We have named the new MAPKs by the numerical order they appear on the phylogenetic tree, according to the suggestion of Ichimura and associates (2002) for Arabi- dopsis and adopted the gene name MPK instead of MAPK. The only exception to this rule was that we kept the original numerical name published for OsMAPK4 (OsMPK4) and OsMAPK5 (OsMPK5).

In Arabidopsis, MAPKs are ordered into four groups (A, B, C, and D) (Ichimura et al. 2002). Phylogenetic analysis by Ligterink and Hirt (2000), using plant MAPKs from multiple species, suggests that plant MAPKs can be grouped into five groups. In this study, phylogenetic analysis and pairwise comparison of 20 AtMPKs and 17 OsMPKs indicated that these MAPKs can be divided into six groups (A, B, C, D, E, and F; Fig. 1). MAPKs in groups $A, B$, and $C$ contain the TEY motif in their activation site, whereas those in the $\mathrm{D}, \mathrm{E}$, and $\mathrm{F}$ groups contain the TDY activation motif. Interestingly, there are 12 AtMPKs containing the TEY motif whereas only 6 OsMPKs belong to the TEY groups. In contrast, 11 OsMPKs have the TDY motif but only eight AtMPKs contain the TDY motif.

Group A contains two rice MAPKs (OsMPK1 and OsMPK5). OsMPK5 and OsMPK1 show the highest similarity with AtMPK3 (Mizoguchi et al. 1996) and AtMPK6 (Ichimura et al. 2000), respectively, and are known to be associated with a variety of biotic and abiotic stress responses. Two tobacco MAPKs, WIPK (Seo et al. 1995) and SIPK (Zhang and Klessig 1997), also show the highest similarity with OsMPK5 and OsMPK1, respectively. Group B contains OsMPK2 and OsMPK6, both of which share high similarity with AtMPK4, a negative regulator of systemic acquired resistance (Petersen et al. 2000). Group C includes OsMPK3 and OsMPK4 and show high similarity with AtMPK1 and AtMPK2. Although encoded by different chromosomes, OsMPK3 and OsMPK 4 are $91 \%$ identical at the amino acid level. OsMPK4 (also known as OsMAPK4 or OsMSRMK3) has been shown to be transcriptionally regulated by various abiotic stresses (Agrawal et al. 2003b; Fu et al. 2002).

Groups D, E, and F include MAPKs that have the TDY motif in their activation site and contain the majority of the rice MAPKs that we found. Group D contains six MAPKs (OsMPK7, OsMPK8, OsMPK9, OsMPK10, OsMPK11, and OsMPK12) and share high similarity with AtMPK20, the only Arabidopsis MAPK belonging to this group (Fig. 1). The OsMPK8 (same as OsWJUMK1) gene is induced by various heavy metals; however, its induction by pathogen attack has

Table 1. The mitogen-activated protein kinase (MAPK) genes in rice ${ }^{a}$

\begin{tabular}{|c|c|c|c|c|c|c|}
\hline New Name & Also known as & Accession number & T-Loop & Amino acids & Group & Chromosome no. \\
\hline OsMPK1 & OsMAPK6* & AB183398 & TEY & 398 & A & 6 \\
\hline OsMPK2 & & BAC 99508 & TEY & 392 & B & 8 \\
\hline OsMPK3 & OsMAP3 & AAG40581 & TEY & 370 & $\mathrm{C}$ & 2 \\
\hline OsMPK4 & OsMAPK4* & CAB61889 & TEY & 369 & $\mathrm{C}$ & 6 \\
\hline OsMPK5 & OsMAPK5* & AF479883 & TEY & 369 & A & 3 \\
\hline OsMPK6 & & NM_197522 & TEY & 386 & B & 10 \\
\hline OsMPK7 & & AK099472 & TDY & 599 & D & 5 \\
\hline OsMPK8 & OsWJUMK1* & AJ512643 & TDY & 569 & D & 1 \\
\hline OsMPK9 & & AAT44204 & TDY & 721 & $\mathrm{D}$ & 5 \\
\hline OsMPK10 & & NM_192924 & TDY & 651 & D & 1 \\
\hline OsMPK11 & & BAD69155 & TDY & 570 & D & 6 \\
\hline OsMPK12 & OsBWMK1* & AF177392 & TDY & 506 & D & 6 \\
\hline OsMPK13 & OsBIMK2 & AY524973 & TDY & 506 & $\mathrm{E}$ & 2 \\
\hline OsMPK14 & & AAS98446 & TDY & 542 & $\mathrm{E}$ & 5 \\
\hline OsMPK15 & & ABA92667 & TDY & 498 & E & 11 \\
\hline OsMPK16 & & NM_192298 & TDY & 568 & E & 1 \\
\hline OsMPK17 & & AAT39148 & TDY & 581 & $\mathrm{~F}$ & 5 \\
\hline
\end{tabular}

${ }^{a}$ Asterisks (*) indicate the previously characterized genes (OsMAPK6, Lieberherr et al. 2005; OsMAPK4, Fu et al. 2002; OsMAPK5, Xiong and Yang 2003; OsWJUMK1, Agrawal et al. 2003b; OsBWMK1, He et al. 1999). OsMPK1 is also known as OsMAPK6 (AB183398) or OsSIPK (AJ535841). OsMPK4 is known as OsMAPK4 (AJ251330) or OsMSRMK3 (AJ512642). OsMPK5 is known as OsMAPK5 (AF479883), OsMAPK2 (AJ250331), OsMAP1 (AF216315), OsMSRMK2 (AJ486975) or OsBIMK1 (AF332873). Other OsMPKs may have been given a name in GenBank but are yet to be characterized and published in refereed journals. Alternative splicing was observed with a number of OsMPKs, such as OsMPK5, OsMPK11, and OsMPK13. The number of amino acids listed in the table is encoded in the large transcript of each $O S M P K$ gene. 
not been demonstrated previously (Agrawal et al. 2003b). The OsMPK12 gene (same as OsBWMK1) was first shown to be transcriptionally induced by the rice blast fungus and wounding (He et al. 1999). Group $\mathrm{E}$ contains four MAPKs (OsMPK13, OsMPK14, OsMPK15, and OsMPK16). OsMPK13 and OsMPK14 are grouped together with AtMPK8, AtMPK9, AtMPK15, and AtMPK17, whereas OsMPK15 and OsMPK16 were shown to share high similarity with AtMPK16. OsMPK17 is the only rice MAPK in Group F and is closely related to AtMPK18 and AtMPK19. To date, relatively little work has been done to identify the function of MAPKs in the D, E, and F groups.

\section{Structural comparison of rice MAP kinases.}

OsMPK proteins have a highly conserved kinase domain containing all 11 subdomains that are characteristic of MAPKs. Like their Arabidopsis counterparts, the rice MAPKs in groups $\mathrm{A}, \mathrm{B}$, and $\mathrm{C}$ have the TEY motif in the activation site and a short C-terminus containing a common docking (CD) domain that consists of the sequence [LHY]Dxx[DE]EpxC (x represents any amino acid) and serves as a docking site for
MAPKKs, phosphatases, and protein substrates (Bardwell et al. 2003; Ichimura et al. 2002) (Fig. 2). Rice MAPKs with the TDY motif do not have a CD domain but have a relatively long C-terminal region. Interestingly, two MAPKs (OsMPK7 and OsMPK10) have potential membrane-spanning regions, indicating that these MAPKs may act to rapidly transduce extracellular signals across the cell membrane.

All rice clones from the rice genome sequencing project have been anchored to the 12 rice chromosome as pseudomolecules as seen on The Institute for Genomic Research (TIGR) website. The 17 OsMPKs are encoded on eight of the rice chromosomes $(1,2,3,5,6,8,10$, and 11) as shown in Figure 3. Several of the $O s M P K s$ appear to be clustered together on the same chromosome.

Chromosomes 5 and 6 have the most OsMPKs located on them, with each encoding four MAPKs. Chromosome 5 encodes OsMPK7, OsMPK9, OsMPK14, and OsMPK17. The OsMPK7, $O s M P K 9$, and $O s M P K 17$ genes are all within $800 \mathrm{~kb}$ of each other, and $O s M P K 7$ and $O s M P K 9$ are separated by $270 \mathrm{~kb}$. Chromosome 6 encodes OsMPK1, OsMPK4, OsMPK11, and OsMPK12, which belong to four of the six $O s M P K$ groups.

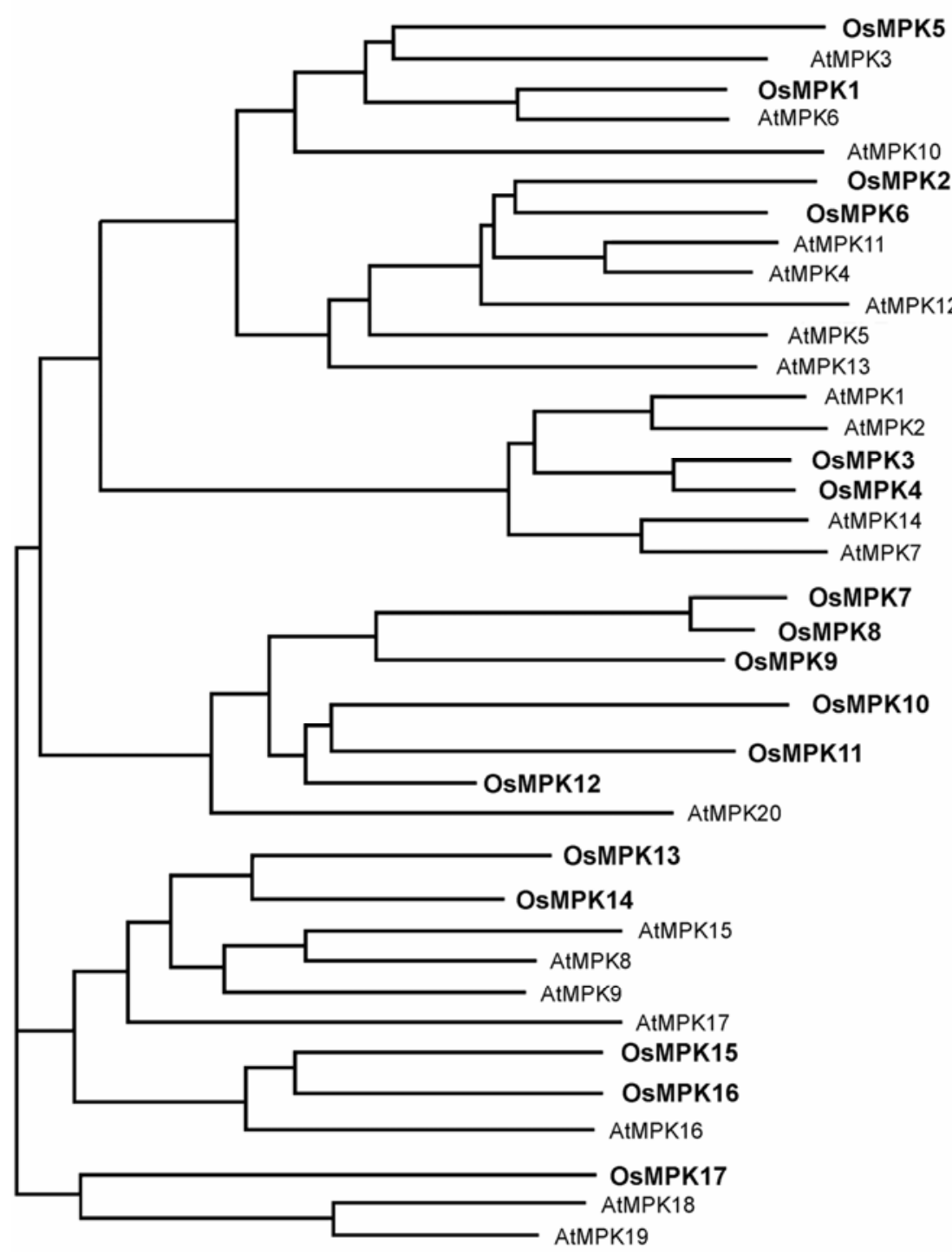

Group (Motif)

A group (TEY)

$B$ group (TEY)

C group (TEY)

D group (TDY)

E group (TDY)

F group (TDY)

Fig. 1. Phylogenetic relationship of the 17 rice mitogen-activated protein kinases (MAPKs). The dendrogram was constructed using Vector NTI Suite software. A total of 20 Arabidopsis MAPKs were included for comparison. 
Chromosome 1 encodes three OsMPKs (OsMPK8, OsMPK10, and $O s M P K 16)$ relatively evenly spaced from each other. Two OsMPKs (OsMPK3 and OsMPK13) were found on chromosome 2. Chromosomes 3, 8, 10, and 11 each only encoded one MAPK (OsMPK5, OsMPK2, OsMPK6, and OsMPK15, respectively).
Expression of $O s M P K s$ in association with pathogen infection and host-cell death.

In order to gain insight into the role of $O s M P K s$ in the hostdefense response, we first examined their expression profiles following the infection of avirulent and virulent isolates of $M$. grisea (Table 2). Previous reports show that OsMPK12

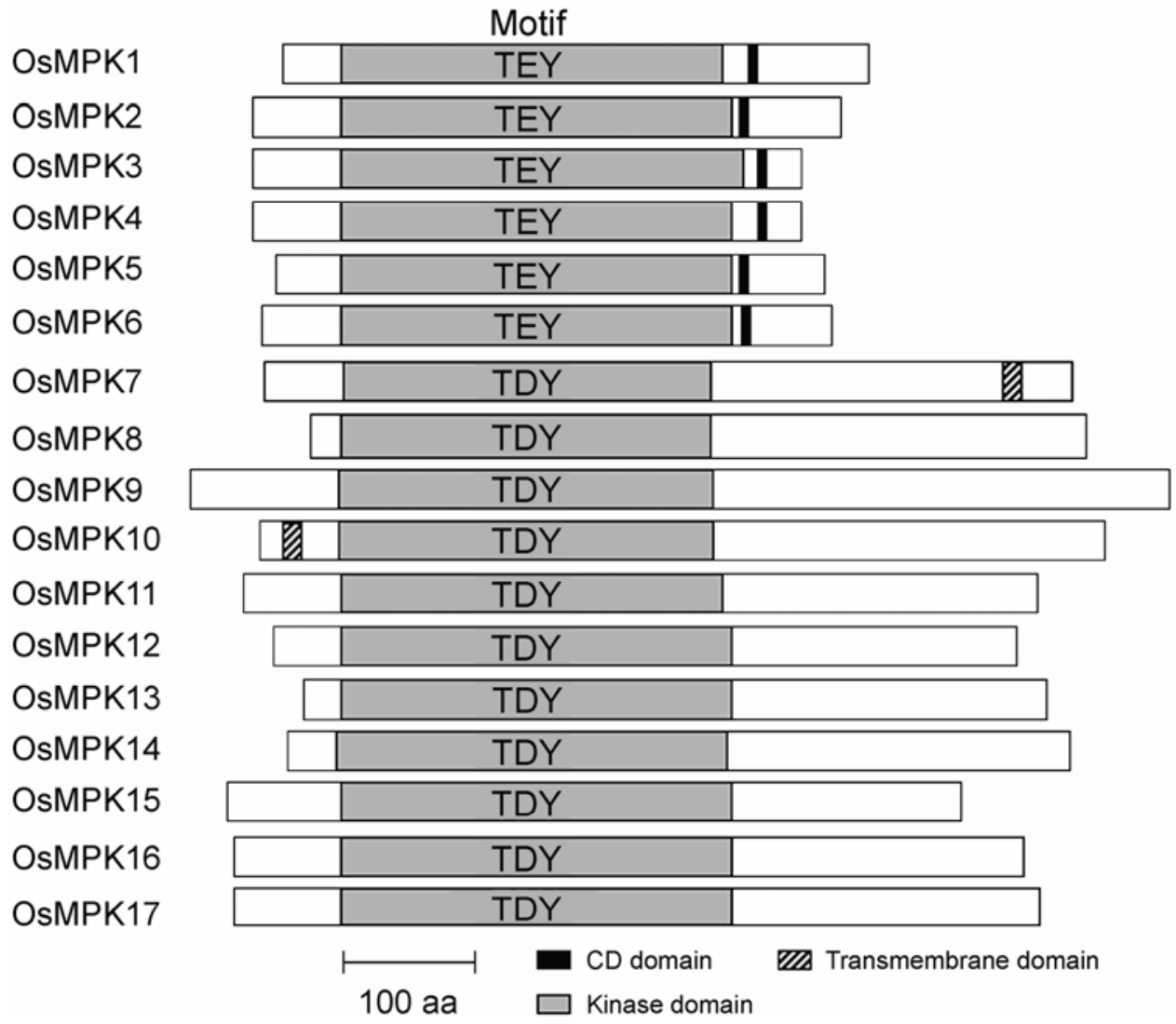

Fig. 2. Structural comparison of the 17 rice mitogen-activated protein kinase.
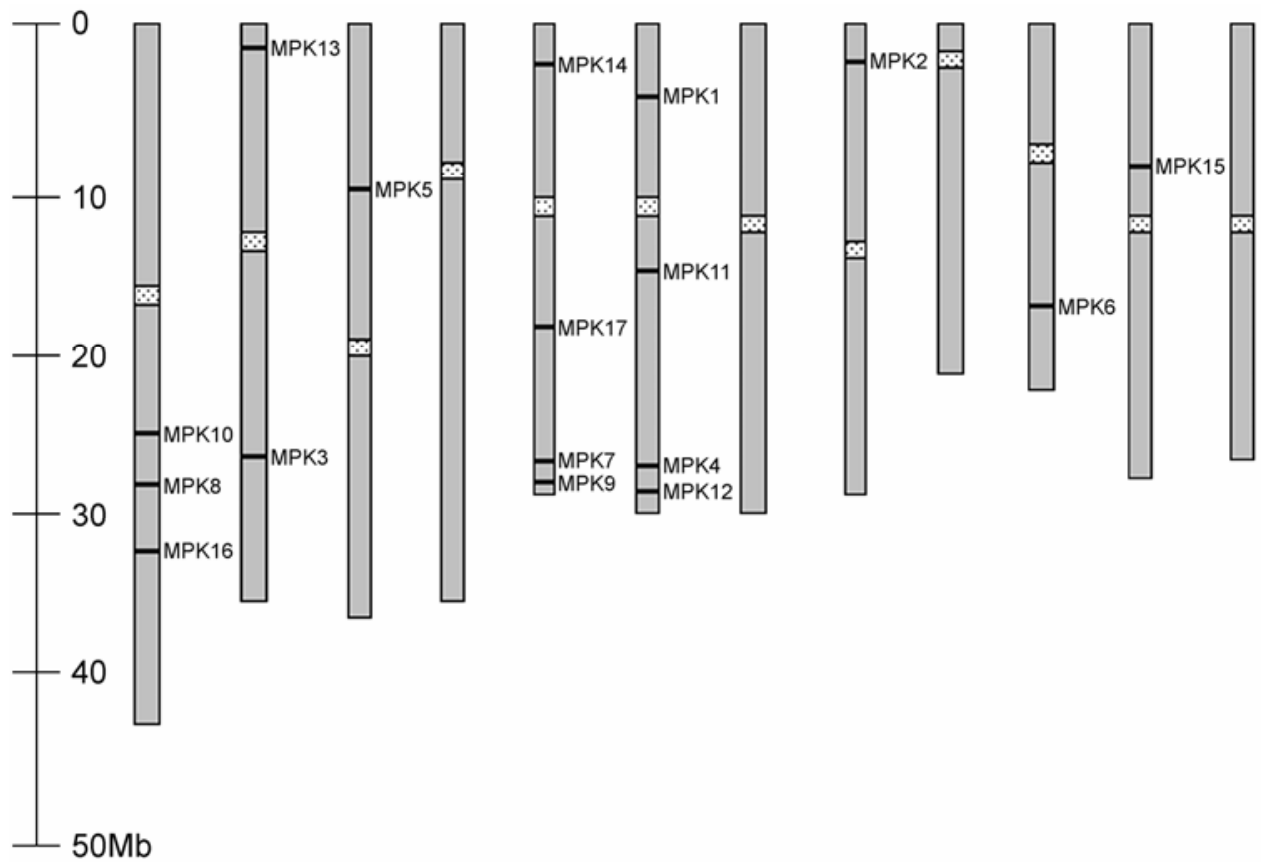

Fig. 3. Chromosome distribution and physical location of the 17 rice mitogen-activated protein kinase genes in rice. The twelve rice chromosomes are numerically labeled with their centromeres indicated by a white box. 
$(O s B W M K 1)$ was induced within hours after fungal inoculation (He et al. 1999); however, OsMPK5 (OsMAPK5) was induced within several days (Xiong and Yang 2003). Because of potential timing differences in gene induction, two experiments were done to detect both early- and late-induced OsMPKs. Identification of early-induced $O S M P K$ s consisted of a spot-inoculation experiment with samples taken in the hours following inoculation. Late-induced $O s M P K$ s were detected by sprayinoculating two-week-old rice seedlings with an avirulent or virulent isolate of the rice blast fungus; samples were taken in days postinoculation.

Inoculation with the blast fungus induced nine $O s M P K \mathrm{~s}$ at the mRNA level (Table 2). The majority of them were induced days after inoculation with the avirulent isolate (Fig. 4). Three
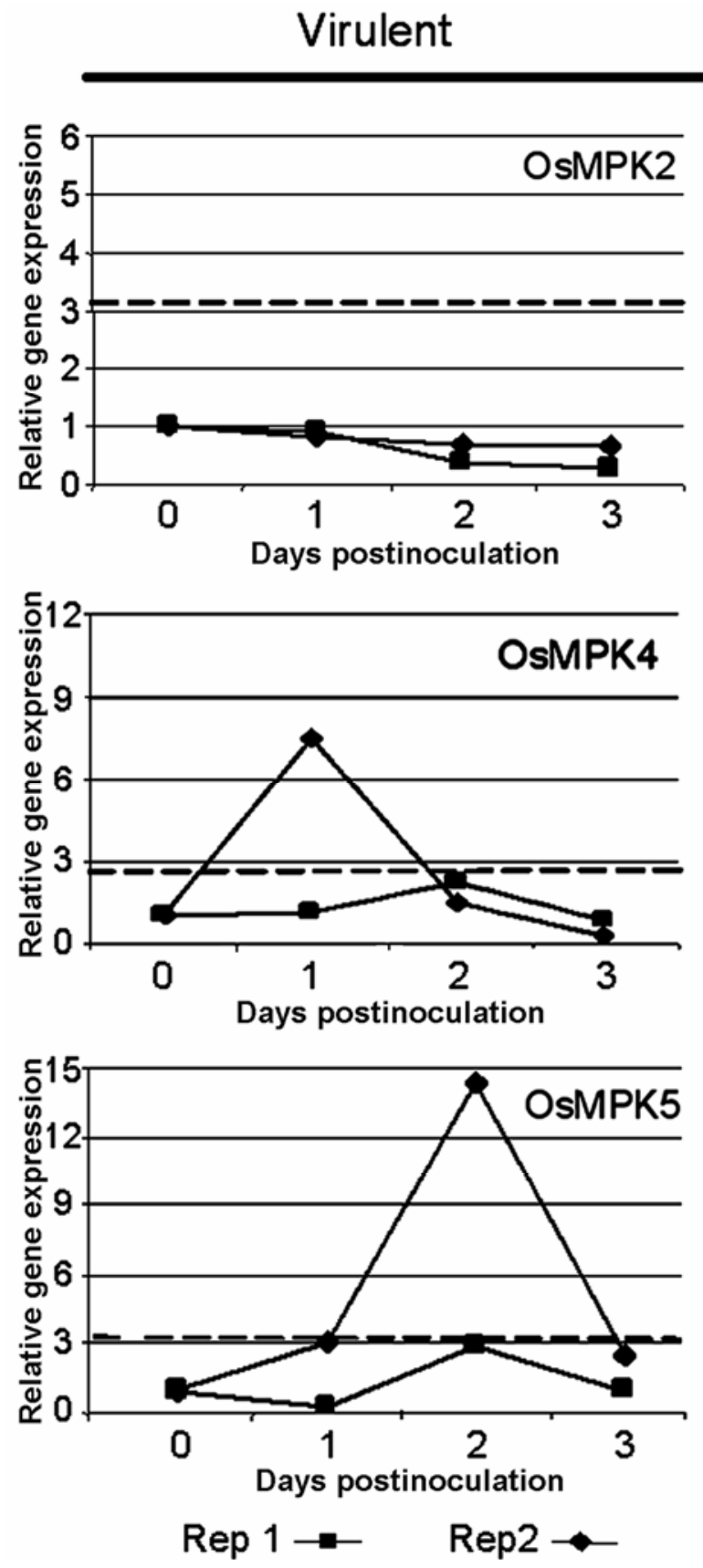

of the OsMPKs (OsMPK5, OsMPK13, OsMPK17) induced by the avirulent blast fungus were also induced by the virulent isolate. No $O s M P K$ was induced exclusively by the virulent isolate at days after inoculation. Only three OsMPKs (OsMPK7, OsMPK12, OsMPK15) were induced earlier than $24 \mathrm{~h}$ after inoculation with the rice blast fungus (Fig. 5). Interestingly, $O s M P K 15$ was induced $2 \mathrm{~h}$ after spot inoculation, returned back to the basal level at $4 \mathrm{~h}$, and then, was induced again $48 \mathrm{~h}$ after inoculation. In the spray-inoculation test, OsMPK 15 was also induced $48 \mathrm{~h}$ after treatment with the avirulent blast fungus (Fig. 4). Only the virulent blast fungus was used in the spot-inoculation study because the induction of these $O s M P K s$ was likely before appressorium penetration and delivery of AvrPita protein into the resistant host carrying
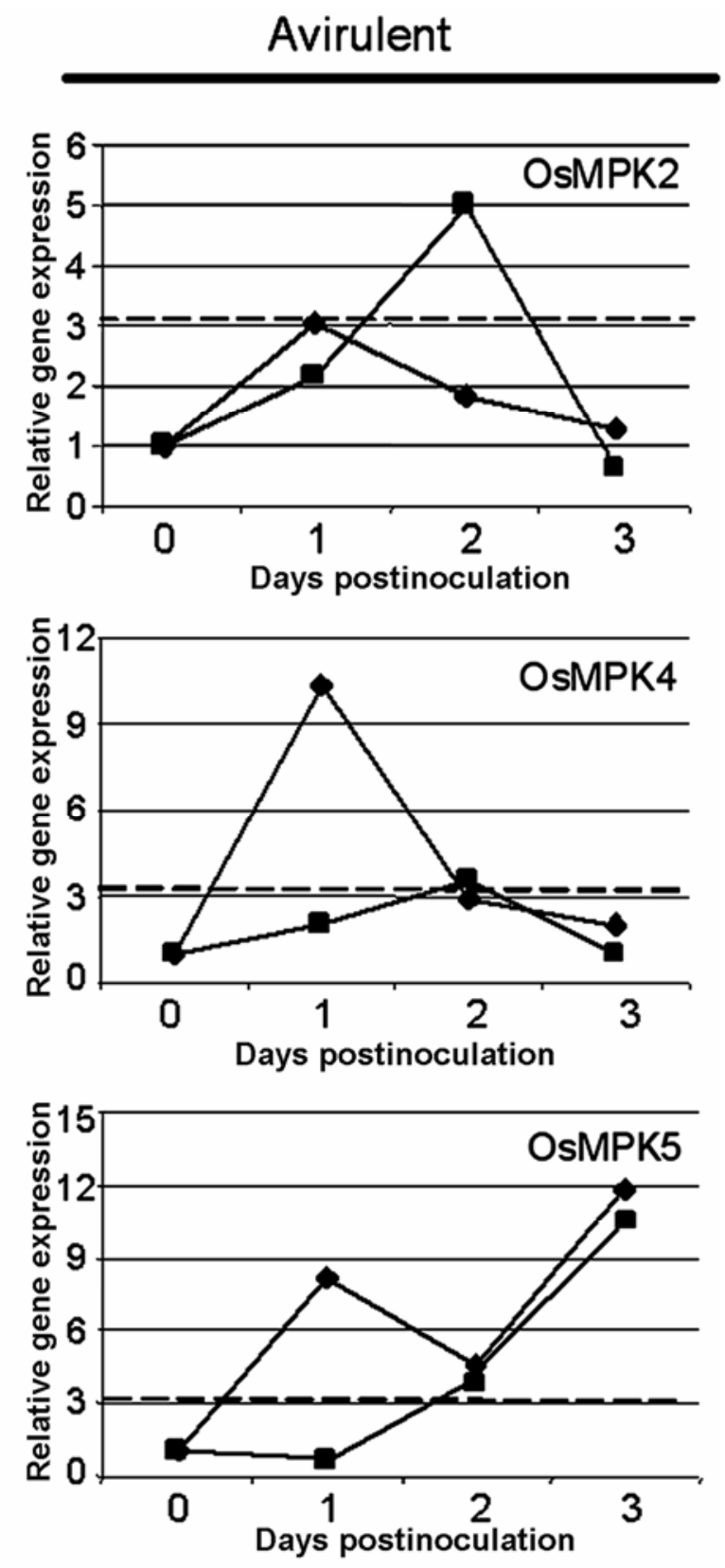

$\operatorname{Rep} 1 \rightarrow-\operatorname{Rep} 2 \multimap$

Continued on next page

Fig. 4. Induction of seven rice mitogen-activated protein kinase $(O s M P K)$ genes by the rice blast fungus. Rice seedlings were spray-inoculated with the avirulent or virulent isolate of Magnaporthe grisea. Total RNAs were isolated from leaf samples collected at 0, 1, 2, and 3 days postinoculation. Quantitative reverse transcription-polymerase chain reaction data were normalized using the rice ubiquitin gene and are shown relative to $0 \mathrm{~h}$. Two sets of biological replicates (Rep1 and Rep2) from independent experiments were presented. Dashed lines indicated threefold induction threshold. 
Virulent
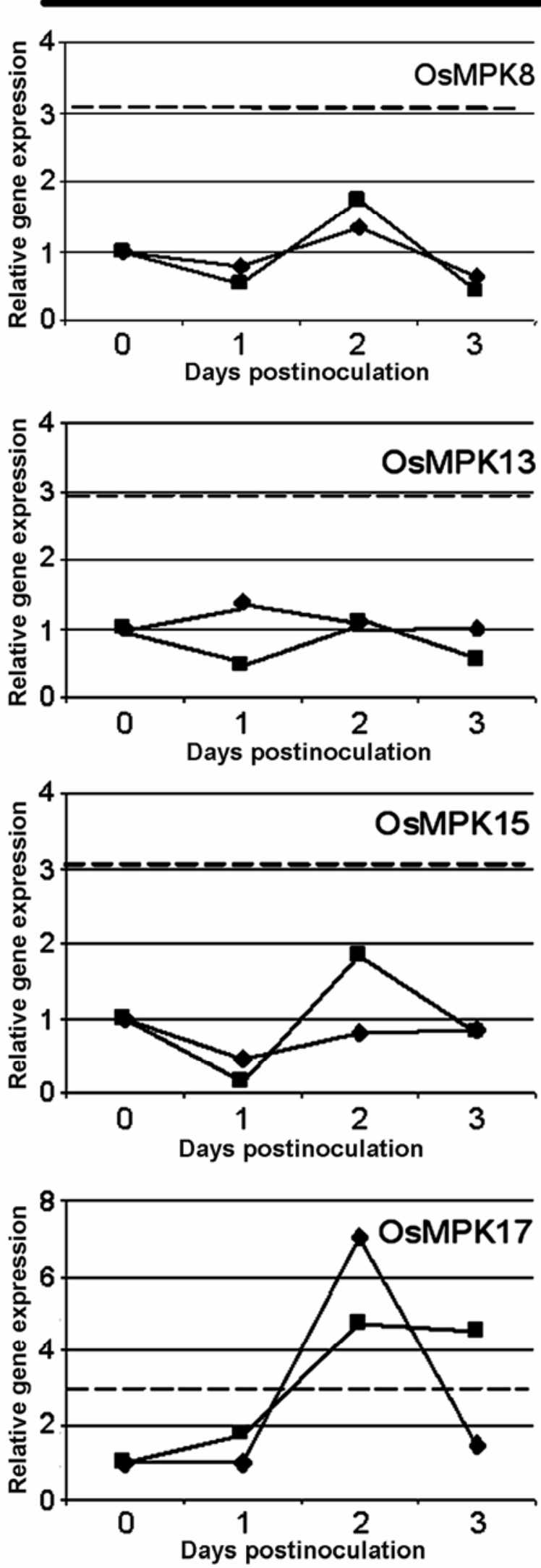

$\operatorname{Rep} 1 \multimap-\operatorname{Rep} 2 \backsim$
Avirulent
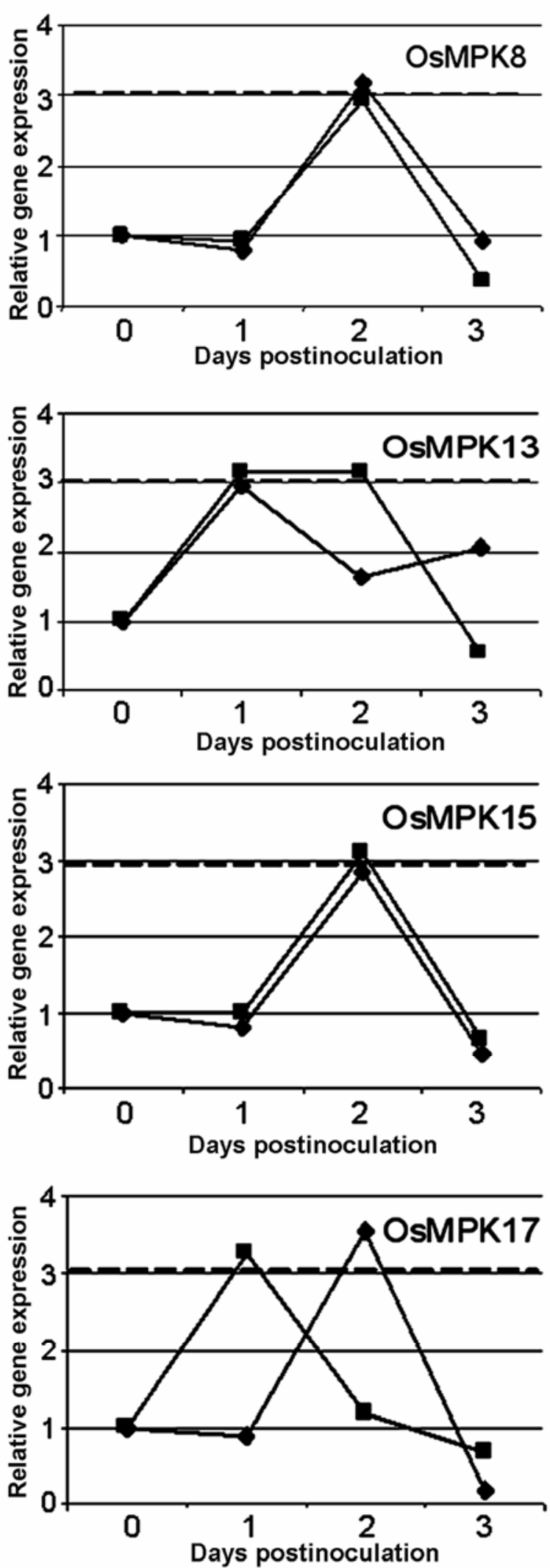

$\operatorname{Rep} 1 \rightarrow-\operatorname{Rep} 2-$

Fig. 4. Continued from preceding page. 
the Pita gene. He and associates (1999) reported that OsBWMK1 (same as OsMPK12) was induced within hours by both a virulent and avirulent rice blast fungus as well as by an appressorium-deficient mutant. The induction of OsMPK5 during the fungal infection also is consistent with what has been previously reported by Xiong and Yang (2003).

Because host-cell death is often associated with the plant defense response, we have examined the expression of $O s M P K s$ during lesion formation. A Sekiguchi lesion-mimic mutant B689A-sl was used because they form spontaneous reddish-brown lesions that are phenotypically similar to hypersensitive cell death (Marchetti et al. 1983; Takahashi et al. 1990). Four OsMPKs (OsMPK 4, OsMPK5, OsMPK8, OsMPK13) were induced in lesioned tissue of the Sekiguchi mutant (Table 2), and each of them showed an approximately fivefold induction (data not shown). These four were also found to be induced within days following fungal inoculation.

\section{Expression of $O s M P K s$ in response}

to defense signaling molecules.

Many studies have shown the involvement of secondary signaling molecules, such as JA, SA, ABA, and ET in the plant defense response (Yang et al. 1997). Therefore, we used QRTPCR to further analyze the expression patterns of nine pathogeninducible $O s M P K$ s in response to JA, SA, ABA, or 1-aminocyclopropane-1-carboxylic acid (ACC) (an ET precursor) treatments (Table 3; Fig. 6). Among the nine $M$. griseainduced genes, $O S M P K 2$ was the only gene not induced by any of the tested defense signal molecules. Four OsMPKs (OsMPK4, OsMPK7, OsMPK12, OsMPK15) were activated by JA treatment, and $O s M P K 7$ was the only one to be considered highly induced (Fig. 6). Three OsMPKs (OsMPK5, $O s M P K 8, O s M P K 12$ ) were induced by ABA, with $O s M P K 5$ the only gene to be considered highly induced by ABA. Our

Table 2. Induction of $O S M P K$ genes during Magnaporthe grisea infection or lesion formation in a lesion-mimic rice mutant ${ }^{\mathrm{a}}$

\begin{tabular}{|c|c|c|c|c|}
\hline \multirow[b]{2}{*}{ OsMPK } & \multicolumn{2}{|c|}{ Late Induction $^{\text {b }}$} & \multirow{2}{*}{$\frac{\text { Early Induction }^{\mathrm{c}}}{\text { Virulent }}$} & \multirow[b]{2}{*}{ Lesion Mimic } \\
\hline & Avirulent & Virulent & & \\
\hline MPK1 & - & - & - & - \\
\hline MPK2 & + & - & - & - \\
\hline MPK3 & - & - & - & - \\
\hline MPK4 & + & - & - & + \\
\hline MPK5 & + & + & - & + \\
\hline MPK6 & - & - & - & - \\
\hline MPK7 & - & - & + & - \\
\hline MPK8 & + & - & - & + \\
\hline MPK9 & - & - & - & - \\
\hline MPK10 & - & - & - & - \\
\hline MPK11 & - & - & - & - \\
\hline MPK12 & - & - & + & - \\
\hline MPK13 & + & + & - & + \\
\hline MPK14 & - & - & - & - \\
\hline MPK15 & + & - & + & - \\
\hline MPK16 & - & - & - & - \\
\hline MPK17 & + & + & - & - \\
\hline \multicolumn{5}{|c|}{$\begin{array}{l}\text { a Late induction represents genes induced later than } 24 \mathrm{~h} \text { after spray- } \\
\text { inoculation with either the avirulent or virulent isolate of the rice blast } \\
\text { fungus. Early induction represents genes induced less than } 24 \mathrm{~h} \text { after } \\
\text { spot-inoculation with the virulent isolate. OsMPKs associated with cell } \\
\text { death were determined by comparing gene induction in lesioned tissue } \\
\text { relative to nonlesioned tissue. + indicates genes that are induced, and - } \\
\text { indicates those not induced. Only genes with a threefold increase relative } \\
\text { to the appropriate } 0 \text {-h sample were considered induced. Data was col- } \\
\text { lected using quantitative reverse transcription-polymerase chain reaction. } \\
\text { All samples were normalized using the rice ubiquitin gene. } \\
\mathrm{b} \text { Inductions within days following spray-inoculation }(0,1,2 \text { and } 3 \text { days). } \\
\text { c Inductions within hours following spot inoculation }(0,1,2,4,6,8,12 \text {, } \\
\text { and } 24 \mathrm{~h} \text { ). }\end{array}$} \\
\hline
\end{tabular}

results are consistent with the reported induction of $O s M P K 5$ (same as OsMAPK5, Xiong and Yang 2003) and OsMPK8 (same as $O s W J U M K 1$, Agrawal et al. 2003b) by ABA. The ETprecursor ACC induced four OsMPKs (OsMPK5, OsMPK12, OsMPK13, OsMPK17) and both OsMPK12 and OsMPK13 were considered highly induced by ACC. Although Xiong and Yang (2003) showed OsMPK5 to be induced by ABA, they did not look at the effect of ACC. OsMPK12 and OsMPK13 were the only two $O s M P K$ s to be induced by SA. Similar to previously reported data, $O s M P K 12$ was the only gene to be induced
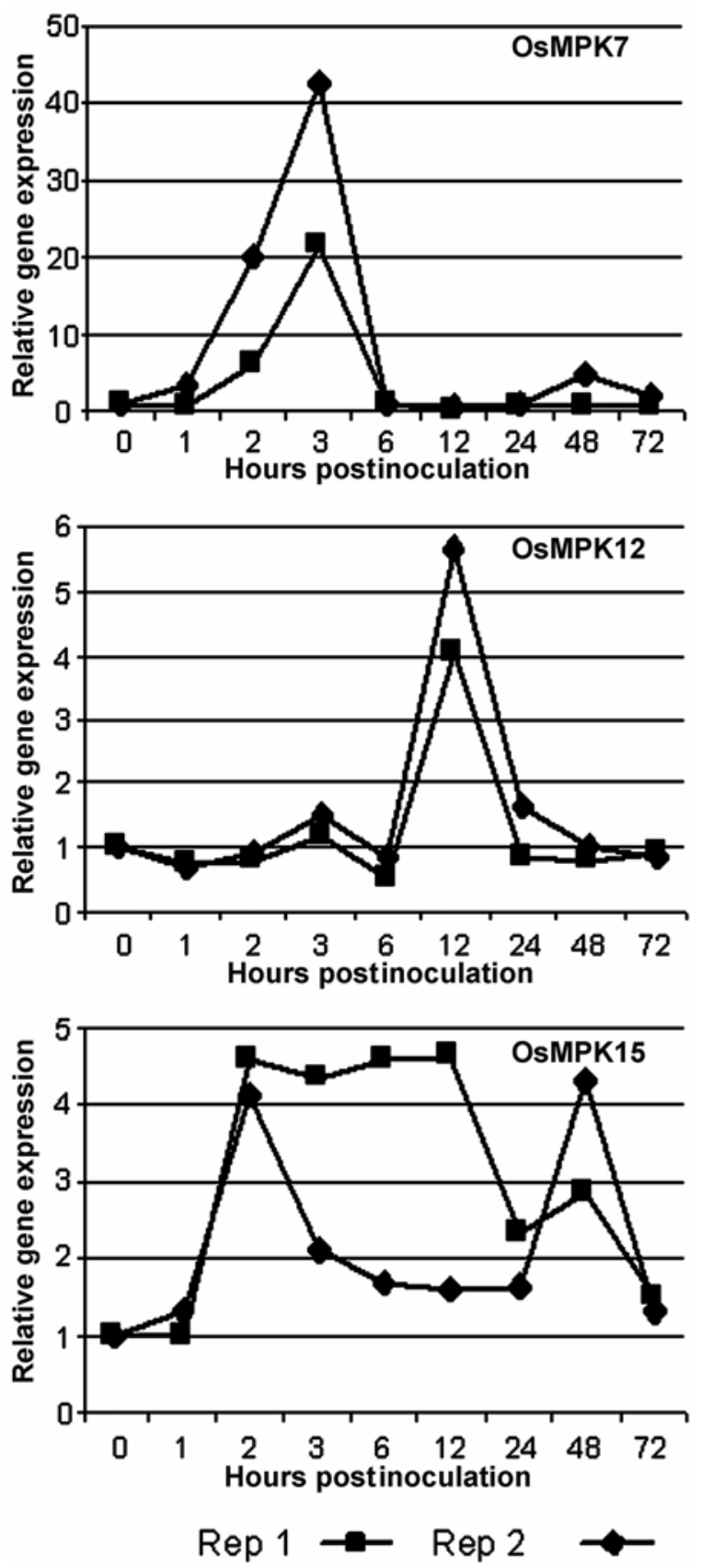

Fig. 5. Early induction of three rice mitogen-activated protein kinase $(O s M P K)$ genes by the rice blast fungus. Detached leaf segments were spot-inoculated with the virulent blast isolate of Magnaporthe grisea. Total RNAs were isolated from leaf segments collected at $0,1,2,4,8$ 12, 24, 48, and $72 \mathrm{~h}$ postinoculation. Quantitative reverse transcription-polymerase chain reaction data were normalized using the rice ubiquitin gene and are shown relative to $0 \mathrm{~h}$. Two sets of biological replicates (Rep1 and Rep2) from independent experiments were presented. Dashed lines indicated threefold induction threshold. 
by all of the chemicals used in this experiment (Agrawal et al. 2003a; Cheong et al. 2003).

\section{DISCUSSION}

A total of 17 OsMPKs were identified in this study, which is three fewer MAPKs than those currently reported in Arabidopsis $(20$ members). The rice genome $(389 \mathrm{Mb})$ is 3.1 times larger than the Arabidopsis genome $(125 \mathrm{Mb})$ and is estimated to encode $30 \%$ more genes than Arabidopsis (International Rice Genome Sequencing Project 2005). Despite the difference in size between the two genomes, little is understood about the biological reasons and mechanisms controlling the number of genes in each organism. Shiu and Bleecker (2003) found the number of Arabidopsis genes encoding the receptor-like kinases to be greater than that found in humans and other organisms with larger genomes than Arabidopsis. A study of the evolution of the CONSTANS-like gene family identified 16 genes in rice and 17 genes in Arabidopsis (Griffiths et al. 2003). While it is possible that more $O s M P K s$ may be identified in the future, it is likely that we have identified most, if not all, of the MAPKs in rice.

Based on the phylogenetic analysis and pairwise comparison of 17 OsMPKs and 20 AtMPKs (Fig. 1), we propose that these MAPKs be divided into six groups. The A, B, and C groups of the MAPKs contain the TEY phosphorylation site, whereas the $\mathrm{D}, \mathrm{E}$, and $\mathrm{F}$ groups have the TDY motif. Interestingly, there are many more OsMPKs in the $\mathrm{D}, \mathrm{E}$, and $\mathrm{F}$ groups (11 members) than in the $\mathrm{A}, \mathrm{B}$, and $\mathrm{C}$ groups (six members). By contrast, Arabidopsis has significantly more MAPKs in the A, B, and C groups (12 members) than in the D, E, and F groups (eight members). It is possible that this ratio (11 TDY OsMPKs vs. six TEY OsMPKs) may be changed with the discovery of new OsMPKs from the rice genome. However, the over-representation of the TDY-type OsMPKs is likely to be maintained in the specific group. For example, six rice MAPKs (OsMPK7, OsMPK8, OsMPK9, OsMPK10, OsMPK11, OsMPK12) are present in the D group, but only one Arabidopsis MAPK (AtMPK20) belongs to the D group (Fig. 1). Currently, it is unknown why the contrasting ratios of TEY vs. TDY MAPKs are present in Arabidopsis and rice or what biological implications the different ratios may entail.

To date most of the MAPKs identified were originally associated with abiotic stresses such as drought and cold and belong to groups A and B (Agrawal et al. 2003a; Ichimura et al. 2002). By contrast, relatively little work has been done on the role of MAPKs in host defense response, particularly in mono-

Table 3. Induction of $O s M P K$ genes by the exogenous treatment ${ }^{\mathrm{a}}$

\begin{tabular}{lcccc}
\hline OsMPK & JA & ABA & SA & ACC \\
\hline MPK2 & - & - & - & - \\
MPK4 & + & - & - & - \\
MPK5 & - & + & - & + \\
MPK7 & + & - & - & - \\
MPK8 & - & + & - & - \\
MPK12 & + & + & + & + \\
MPK13 & - & - & + & + \\
MPK15 & + & - & - & - \\
MPK17 & - & - & - & +
\end{tabular}

${ }^{a}$ Total RNAs were isolated from leaf samples collected at $0,1,2,4,6,12$, and $24 \mathrm{~h}$ after treatments and were used for quantitative reverse transcription-polymerase chain reaction. All samples were normalized using the rice ubiquitin gene. + indicates genes that are induced, and indicates those not induced. Only genes with a threefold increase relative to the appropriate 0 -h sample were considered induced. $\mathrm{JA}=$ jasmonic acid, $\mathrm{ABA}=$ abscisic acid, $\mathrm{SA}=$ salicylic acid , and $\mathrm{ACC}=1$-aminocyclopropane-1-carboxylic acid. cot plants. In this study, we surveyed the expression patterns of $17 O s M P K s$ in order to gain insight into their involvement in the plant defense response. The rice blast fungus was found to induce at least nine $O s M P K \mathrm{~s}(O s M P K 2, O s M P K 4, O s M P K 5$, OsMPK7, OsMPK8, OsMPK12, OsMPK13, OsMPK15, $O s M P K 17)$. Four of them were induced only by the avirulent pathogen and may play a specific role in $R$ gene-mediated disease resistance. Three $O s M P K$ s were induced by both the virulent and avirulent rice blast fungus. The other three OsMPKs were induced within hours after spot inoculation with the rice blast fungus. Among the nine blast-induced $O s M P K s$, four of them (OsMPK4, OsMPK5, OsMPK8, OsMPK12) are also known to be inducible by abiotic stresses (Agrawal et al. 2003a), suggesting the potential role of these OsMPKs in mediating both biotic and abiotic stress signaling.

Four OsMPKs (OsMPK 4, OsMPK5, OsMPK8, and $O s M P K 13$ ) were found to be associated with cell death in the lesioned tissue of the Sekiguchi lesion-mimic mutant as com-
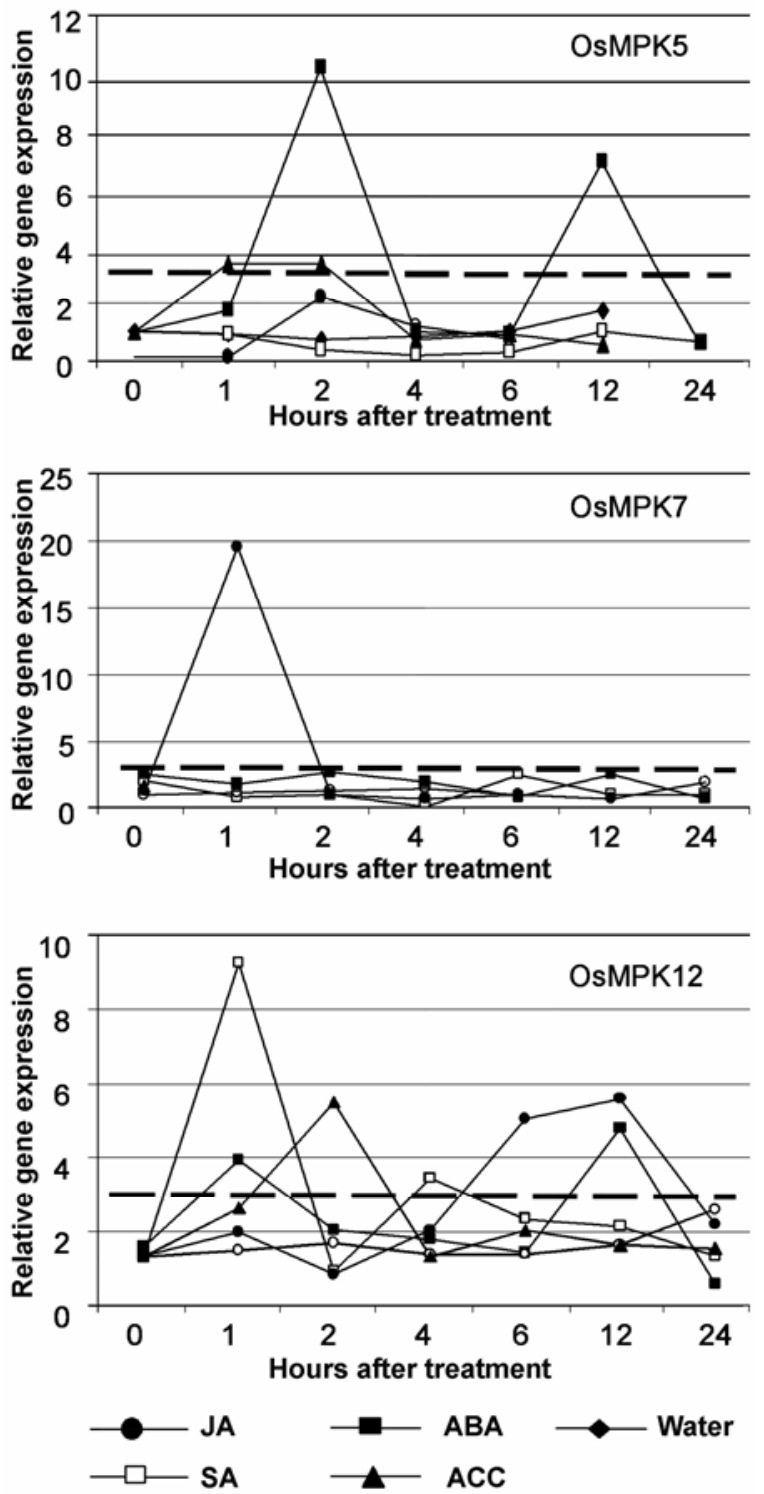

Fig. 6. Induction patterns of three rice mitogen-activated protein kinase $(O s M P K)$ genes by jasmonic acid (JA), salicylic acid (SA), abscisic acid (ABA), and the ethylene precursor 1-amino-cyclopropane-1-carboxylic acid (ACC). Samples were taken at 0, 1, 2, 4, 6, 12, and $24 \mathrm{~h}$ after chemical treatments. Quantitative reverse transcription-polymerase chain reaction data were normalized using the rice ubiquitin gene and are shown relative to $0 \mathrm{~h}$. Dashed lines indicated threefold induction threshold. 
pared with healthy leaf tissue. MAPKs have recently been shown to be involved in signaling host-cell death. Pedley and Martin (2004) found that the activation of two MAPKs in tomato was involved in triggering host-cell death and was associated with Pto-mediated resistance to Pseudomonas syringae pv. tomato. All four of the OsMPKs induced in lesioned tissue were also found to be induced within days of pathogen infection in the resistant interaction. Therefore, these $O s M P K s$ may be involved in the cell-death pathway controlled by the Sekiguchi mutation and pathogen-induced hypersensitive response.

The fact that some $O s M P K s$ were induced either early or late suggests a dual role of MAPKs in the rice defense response. The early induction suggests an initial rapid response (before the fungal penetration) to a pathogen that may be independent of $R$ gene-mediated resistance. The late induction may be dependent on $R$ gene-mediated resistance as seen by the $O s M P K s$ induced following penetration by the avirulent isolate (carrying AvrPita) of the rice blast fungus. It is possible that some of these MAPKs may be involved in signaling hypersensitive cell death.

As expected, the $M$. grisea-inducible $O s M P K$ s were also activated by various defense signaling molecules. In Arabidopsis, there are about $60 \mathrm{MAPKKKs,} 10 \mathrm{MAPKKs}$, and $20 \mathrm{MAPKs}$ and it has been hypothesized that MAPKs act as a converging point for many different signals (Zhang and Klessig 2001). The wide range of induction patterns seen in our experiments may help strengthen this hypothesis. Several $O s M P K s$, such as OsMPK5, OsMPK8, OsMPK12, and OsMPK13, were found to be induced by multiple chemicals, suggesting their potential role in mediating cross-talks between defense signaling pathways. Only one MAPK gene (OsMPK2) was induced by the rice blast fungus but not by any of the chemicals used in this experiment. One explanation for this is the fact that we only used four of the most common defense signaling molecules. OsMPK2 may be induced by other signaling compounds or by the synergistic effect of two or more defense signaling molecules.

QRT-PCR was used to measure the expression patterns of $O s M P K$ s. This method is accurate but very sensitive. For this reason, we only considered a gene induced if it had a threefold induction over the 0 -h control. By setting a high threshold, we may have missed genes that were induced at lower levels by the blast fungus or signaling chemicals. However, our expression data are in agreement with the induction patterns of the four previously characterized rice MAPK genes.

To our knowledge, this is the first report of genome-wide analysis and expression profiling of the MAPK gene family in rice. This study was intended as a survey of the MAPKs in rice and to provide a foundation for future research. Further biochemical and functional genomic analyses of OsMPKs and their up- and downstream components are needed to elucidate the role of the MAPK cascades in rice defense response.

\section{MATERIALS AND METHODS}

\section{Identification of $O s M P K s$.}

Several sources are available that provide robust bioinformatic analysis of the rice genome and act as a platform for identifying specific genes and gene families. One of the most complete annotated databases is The Whole Rice Genome Automated Annotated Database at TIGR (Yuan et al. 2003). Through TIGR, over $90 \%$ of the rice genome has been annotated, assigned a putative function, and anchored to a specific chromosome. Rice genes annotated as putative MAPKs were retrieved from the TIGR whole rice automated annotated database by BLAST analysis of the database with conserved MAPK functional domains and name search for putative MAPKs.

We set several criteria to select for rice MAPKs, including: i) significant sequence homology at the amino acid level with other known MAPKs; ii) 11 conserved subdomains associated with MAPKs; as well as iii) the TDY or TEY motif in the activation site (Hanks and Hunter 1995). Only genes that fit these criteria were considered as MAPKs and examined in this study.

\section{Physical mapping of $O s M A P K s$ on rice chromosome.}

TIGR has linked all annotated contigs as pseudomolecules representing the 12 chromosomes. Using these pseudomolecules, all rice MAPKs were physically mapped to their specific location on each chromosome.

\section{Sequence alignment and phylogenetic analysis.}

The protein sequences for the 20 MAPKs in Arabidopsis was obtained in GenBank, using the accession numbers listed by Ichimura and associates (2002). The predicted protein sequences of the 17 OsMAPKs and 20 AtMAPKs were aligned, and a dendrogram was generated using Vector NTI software (Informax, North Bethesda, MD, U.S.A.). Alignments and phylogenetic analysis were also created using Clustal W through the Biology Workbench in order to double check the results obtained through Vector NTI.

\section{Rice materials and lesion-mimic mutant.}

Rice cultivars Nipponbare and Drew (Oryza sativa L. sp. japonica) were grown in a computer-controlled greenhouse at

Table 4. The forward and reverse primer sequences used in quantitative reverse transcription-polymerase chain reaction for detection of $O s M P K$ expression

\begin{tabular}{|c|c|c|c|}
\hline MAPK & Forward $\left(5^{\prime}-3^{\prime}\right)$ & Reverse $\left(5^{\prime}-3^{\prime}\right)$ & Product size $^{\mathrm{a}}$ \\
\hline 1 & CGACAGTGATCACTAGTTGT & GCAGAATTTAGGCCGTCATC & 235 \\
\hline 2 & GAAGAACGGAAGCAGATCAC & GTCCGAATTTGCGATGTCAG & 148 \\
\hline 3 & CGATGATCTTCAACTGTCCC & CATACACCAAGTAATGGTCC & 188 \\
\hline 4 & CTGTGGACCTCTACTTGTAG & TCTCAGCAAGTCAGCATAGC & 166 \\
\hline 5 & ACGAGGACCAAATGAAGCAGC & AGCAGCCACAACTTGCAGAGA & 205 \\
\hline 6 & GTCAGACTACTCTGATAGGC & GAGCACTCCTCGTAAAGTAG & 145 \\
\hline 7 & TCATCTGGAGGGAATCCTTG & TGCTCATTCGCCCAACAAGT & $163579 *$ \\
\hline 8 & GTCAGGCAGTTGTGGAATTG & СТССТTTCTTCAАСCTTCGC & 147 \\
\hline 9 & GATTCCAGGTAGAACAGGAC & GCTCTCTTTCTGAGCTATCC & $169269^{*}$ \\
\hline 10 & GTGGCTCAGCAATTCCAATG & TGCCACTTGTGAAACCTGAG & $208808 *$ \\
\hline 11 & TCAGGTCTACTATTGTTCAC & GCAATACTGGACCAACAACTC & $200503 *$ \\
\hline 12 & TCCAAGTACACACCAGCTATTG & ATAGCATCTAAGGAGGGTGTTC & 148 \\
\hline 13 & TGGAGTATCACCCACAGATG & CTGTAGTTCTCCTCAAGGTG & $116524 *$ \\
\hline 14 & AGAATGGTATCTCTGAGGAC & AGAGCCTAGAGTATCAGCTC & 191 \\
\hline 15 & ACAGCCAGTGTCACTGAGGATC & GAACAGTTACCGTAACGCAG & $151271^{*}$ \\
\hline 16 & ACCCACAGCAGAAGCTTACA & AGACGATGTGAAGTCACCAG & 155 \\
\hline 17 & AGTACCATCCTCAGATGATGC & GTCCATCTGTCACTGATGAG & 170 \\
\hline
\end{tabular}

a Asterisks (*) indicate the intron size if genomic DNA is used as the template. 
$28^{\circ} \mathrm{C}$ under a $14-\mathrm{h}$ light period. Two-week-old rice seedlings were used for pathogen infection or chemical treatments. A Sekiguchi lesion mutant (B689A-sl; Marchetti et al. 1983) was grown under the same conditions as those described above. For cell-death induction of $O s M P K s$, RNA samples were extracted from lesion and nonlesion tissues of the lesion-mimic mutant. Induction of $O s M P K s$ is relative to their basal expression in the nonlesion tissue.

\section{Pathogen inoculation and chemical treatments.}

The fungal isolates used in the study are $18 / 1$ of the IC-17 pathotype, which is avirulent on Drew, and its race-change mutant 18/2-1, which is virulent on Drew (Harp and Correll 1998). Rice leaves were infected with $M$. grisea, using spotand spray-inoculation methods. The spot-inoculation study was done according to the method described by Jia and Valent (2001). Briefly, leaf segments (5 to $6 \mathrm{~cm}$ in length) from the top fully-expanded leaf of one-month-old plants were set on filter papers soaked with water in petri dishes. Droplets containing approximately 50 spores and $0.02 \%$ Tween-20 were applied onto leaf segments. The petri dishes were then covered, and leaf segments were maintained at room temperature under constant white light. Samples were taken at 0, 1, 3, 6, 12, 24, 48 , and $96 \mathrm{~h}$ after inoculation.

The spray inoculation method was carried out by spraying two-week-old seedlings of the rice cultivar Drew with the blast fungus at a concentration of 250,000 spores per ml (containing $0.02 \%$ Tween-20). The inoculated plants were moved to a dew chamber at $22^{\circ} \mathrm{C}$ for $24 \mathrm{~h}$ and were then shifted back to a growth chamber. Leaf tissues were harvested $0,1,2$, and 3 days after inoculation.

For chemical treatments, two-week-old rice seedlings of the rice cultivar Drew were sprayed with SA $(1.5 \mathrm{mM})$, JA $(0.1$ $\mathrm{mM}), \operatorname{ABA}(0.1 \mathrm{mM})$, and ACC $(0.1 \mathrm{mM})$, the precursor of ET. Leaf samples were taken at $0,1,2,4,6,12$, and $24 \mathrm{~h}$ after treatments.

\section{RNA isolation and reverses transcription.}

Total RNAs were isolated from leaf tissue with TRIzol reagent (Invitrogen, Carlsbad, CA. U.S.A). Total RNA was first treated for $30 \mathrm{~min}$ at $37^{\circ} \mathrm{C}$ with DNAase I (Promega Inc., Madison, WI, U.S.A.) in order to remove potential genomic DNA contamination. First-strand cDNA was then synthesized from $5 \mu \mathrm{g}$ of total RNA by reverse transcription using Superscript II reverse transciptase (Invitrogen) and the oligo dT primer. For each sample, two separated reverse transcription reactions were done and then pooled together and diluted up to $200 \mu \mathrm{l}$. QRT-PCR for all OsMPKs were done from the same pool of cDNA for each treated sample in order to insure uniformity of the results. At least two technical replicates were included in the QRT-PCR for each sample. In addition, at least two biological replicates from independent experiments were used for expression analysis of all the $O S M P K$ genes.

\section{Quantitative real-time PCR.}

A pair of gene-specific primers was chosen for each $O s M P K$ and their specificities were confirmed in an agarose gel before they were used in the real-time PCR analysis (Table 4). When possible, primers were also designed to span intron-splicing sites in an attempt to reduce the effect of potential genomic DNA contamination. Each PCR reaction was prepared as follows: $12.5 \mu$ of SYBR-Green PCR mater mix (Qiagen, Valencia, CA, U.S.A.), $0.625 \mu \mathrm{l}$ of each primer $(10 \mu \mathrm{M}), 10.25 \mu \mathrm{l}$ of water, and $1 \mu \mathrm{l}$ of each reverse-transcribed cDNA product. Quantitative real-time PCR was carried out using the Mx3000P real-time PCR system (Stratagene, La Jolla, CA, U.S.A.). The thermocycler program had an initial $95^{\circ} \mathrm{C}$ denatu- ration step followed by 40 cycles consisting of a 30-s denaturation at $95^{\circ} \mathrm{C}$, a 30 -s annealing at $55^{\circ} \mathrm{C}$, and a 30 -s extension step at $72^{\circ} \mathrm{C}$. At the end of each reaction, a disassociation curve was created, using a single cycle consisting of a 1-min denaturation at $95^{\circ} \mathrm{C}$ and a $30-\mathrm{s}$ annealing at $55^{\circ} \mathrm{C}$. This was followed by a slow temperature increase to $95^{\circ} \mathrm{C}$. The disassociation curve was used to help detect the presence of primer dimers or other unwanted amplification products that would produce a detectable cycle threshold $(\mathrm{Ct})$ value and negatively skew the results.

The rice ubiquitin gene, a constitutively expressed housekeeping gene, was used to normalize samples. The comparative $\mathrm{Ct}$ method, as described by Bovy and associates (2002), was used to express all genes within a sample relative to the time 0 sample. Briefly, the relative $\mathrm{Ct}$ method consists of the following formula $2^{-(\Delta \mathrm{Ct} \text { treatment- } \Delta \mathrm{Ct} \text { control })}$, where $\left(\mathrm{Ct}^{\text {target gene }}\right.$ to $\left.\mathrm{Ct}^{\text {normalizer }}\right)$ and $\left(\mathrm{Ct}^{\text {time zero }}\right.$ to $\left.\mathrm{Ct}^{\text {normalizer }}\right)$ represent $\Delta \mathrm{Ct}^{\text {treatment }}$ and $\Delta \mathrm{Ct}^{\text {control }}$, respectively. In this study, only genes that showed a threefold increase compared with the 0 -h control were considered induced.

\section{ACKNOWLEDGMENTS}

We thank D.-S. Park for providing assistance in figure preparation. This work was supported by grants from United States Agency for Internationa Development International Rice Research Institute and the Arkansas Rice Research and Promotion Board.

\section{LITERATURE CITED}

Agrawal, G. K., Rakwal, R., and Iwahashi, H. 2002. Isolation of novel rice (Oryza sativa L.) multiple stress responsive MAP kinase gene, OsMSRMK2, whose mRNA accumulates rapidly in response to environmental cues. Biochem. Biophys. Res. Commun. 294:1009-1016.

Agrawal, G. K., Iwahashi, H., and Rakwal, R. 2003a. Rice MAPKs. Biochem. Biophys. Res. Commun. 302:171-180.

Agrawal, G. K., Agrawal, S. K., Shibato, J., Iwahashi, H., and Rakwal, R. 2003b. Novel rice MAPK kinase OsMSRMK3 and OsWJUMK1 involved in encountering diverse environmental stresses and developmental regulation. Biochem. Biophys. Res. Commun. 300:775-783.

Bardwell, A. J., Abdollahi, M., and Bardwell, L. 2003. Docking sites on mitogen-activated protein kinase (MAPK), MPK phosphatases and the EIK1 transcription factor compete for MAPK binding and are crucial for enzyme activity. Biochem. J. 370:1077-1085.

Bovy, A., Vos, R.d., Kemper, M., Schijlen, E., Perejo, M. A., Muir, S. Collins, G., Robinson, S., Verhoeyen, M., Hughes, S., and SantosBuelga, C. 2002. High-flavonol tomatoes resulting from heterologous expression of the maize transcription factor genes LC and C1. Plant Cell 14:2509-2526.

Cheong, Y. H., Moon, B. C., Kim, J. K., Kim, C. Y., Kim, M. C., Kim, I H., Park, C. Y., Kim, J. C., Park, B. O., Koo, S. C., Yoon, H. W., Chung, W. S., Lim, C. O., Lee, S. Y., and Cho, M. J. 2003. BWMK1, a rice mitogen-activated protein kinase, locates in the nucleus and mediates pathogenesis-related gene expression by activation of a transcription factor. Plant Physiol. 132:1961-1972.

Fu, S.-F., Chou, W.-C., Huang, D.-D., and Huang, H.-J. 2002. Transcriptional regulation of a rice mitogen-activated protein kinase gene, OsMAPK4, in response to environmental stress. Plant Cell Physiol. 43:958-963.

Griffiths, S., Dunford, R. P., Couplant, G., and Laurie, D. A. 2003. The evolution of CONSTANS-like gene families in barley, rice and Arabidopsis. Plant Physiol. 131:1855-1867.

Hammond-Kosack, K. E., Tang, S., Harrison, K., and Jones, J. D. G. 1998. The tomato $C f-9$ disease resistance gene function in tobacco and potato to confer responsiveness to the fungal avirulence gene product Avr9. Plant Cell 10:1251-1266.

Hanks, S. K., and Hunter, T. 1995. Eukaryotic protein kinase family: Kinase (catalytic) domain structure and classification. FASEB (Fed Am. Soc. Exp. Biol.) J. 9:576-596.

Harp, T. L., and Correll, J. C. 1998. Recovery and characterization of spontaneous, selenate-resistant mutants of Magnaporthe grisea, the rice blast pathogen. Mycologia 90:954:963.

Huang, H. J., Fu, S. F., Tai, Y. H., Chou, W. C., and Huang, D. D. 2002. Expression of Oryza sativa MAP kinase gene is developmentally regulated and stress-responsive. Plant Physiol. 114:958-963. 
He, C., Fong, S. H. T., Yang, D., and Wang, G. L. 1999. BWMK1, a novel MAP kinase induced by fungal infection and mechanical wounding in rice. Mol. Plant-Microbe Interact. 12:1064-1073.

Hirt, H. 1997. Multiple roles of MAPK kinases in plant signal transduction. Trends Plant Sci. 2:131-144.

Ichimura, K., Mizoguchi, T., Yoshida, R., Yuasa, T., and Shinozaki, K. 2000. Various abiotic stresses rapidly activate Arabidopsis MAP kinases ATMPK4 and ATMPK6. Plant J. 24:655-665.

Ichimura, K., Tena G, Sheen, J., Henery, Y., Champion, A., Kreis, M., Zhang, S., Hirt, H., Wilson, C., Ellis, B. E., Morris, P., Innes, R., Ecker, J., Scheel, D., Klessig, D., Machida, Y., Mundy, J., Ohashi, Y., and Walker, J. C. 2002. Mitogen-activated protein kinase cascades in plant: A new nomenclature. Trends Plant Sci. 7:301-308.

International Rice Genome Sequencing Project. 2005. The map-based sequence of the rice genome. Nature 436:793-800.

Jia, Y., and Valent, B. 2001. Rapid determination of Magnaporthe grisea pathogenicity towards rice. Abstract. Phytopathology 91:S44.

Jonak, C., Okresz, L., Bogre, L., and Hirt, H. 2002. Complexity, cross talk and integration of plant MAP kinase signaling. Curr. Opin. Plant Biol. 5:415-24.

Lieberherr, D., Thao, N. P, Nakashima, A., Umemura, K., Kawasaki, T., and Shimamoto, K. 2005. A sphingolipid elicitor-inducible mitogenactivated protein kinase is regulated by the small GTPase OsRac1 and heterotrimeric G-protein in rice. Plant Physiol. 138:1644-1652.

Ligterink, W., and Hirt, H. 2001. Mitogen-activated protein (MAP) kinase pathways in plants: Versatile signaling tools. Int. Rev. Cytol. 201:209-275.

Marchetti, M. A., Bollich, C. N., and Uecker, F. A. 1983. Spontaneous occurrence of the Sekiguchi lesion in two American rice lines: Its induction, inheritance, and utilization. Phytopathology 73:603-606.

Mizoguchi, T., Irie, K., Hirayama, T., Hayashida, N., Yamaguchi-shinozaki, K., Matsumoto, K., and Shiozaki, K. 1996. A gene encoding a mitogenactivated protein kinase kinase kinase is induced simultaneously with genes for a mitogen-activated protein kinase and S6 ribosomal protein kinase by touch, cold and water stress in Arabidopsis thaliana. Proc. Natl. Acad. Sci. U.S.A. 93:765-769.

Nakagami, H., Pitzschke, A., and Hirt, H. 2005. Emerging MAP kinase pathways in plant stress signaling. Trends Plant Sci. 10:339-346.

Pedley, K. F., and Martin, G. B. 2004. Identification of MAPKs and their possible MAPK kinase activators involved in the Pto-mediated defense response of tomato. J. Biol. Chem. 279:49229-49235.

Pedley, K. F., and Martin, G. B. 2005. Role of mitogen-activated protein kinases in plant immunity. Curr. Opin. Plant Biol. 8:541-547.

Petersen, M., Brodersen, P., Naested, H., Andreasson, E., and Lindhart, U. 2000. Arabidopsis MAP Kinase 4 negatively regulates systemic acquired resistance. Cell 103:1111-1120.

Romeis, T., Piedras, P., Zhang, S., Klessig, D. F., Hirt, H., and Jones, J. 1999. Rapid Avr9- and Cf-9-dependent activation of MAP kinases in tobacco cell cultures and leaves: Convergence in resistance gene, elicitor, wound and salicylate responses. Plant Cell 11:273-297.
Shiu, S. H., and Bleecker, A. B. 2003. Expansion of the receptor-like kinase/pelle gene family and receptor-like proteins in Arabidopsis. Plant Physiol. 132:530-543.

Seo, S., Sano, H., and Ohashi, Y. 1995. Jasmonate-based wound signal transduction requires activation of WIPK, a tobacco mitogen-activated protein kinase. Plant Cell 11:289-298.

Song, F., and Goodman, R. M. 2002. OsBIMK1, a rice MAP kinase gene involved in disease resistance responses. Planta 215:997-1005.

Takahashi, A., Kawasaki, T., Shii, K., Kodama, K., Satoh, O., and Shimamoto, K. 1990. Lesion mimic mutants of rice with alterations in early signaling events of defense. Plant J :535-545.

Tena, G., Asai, T., Chiu, W. L., and Sheen, J. 2001. Plant mitogen-activated protein kinase signaling cascades. Curr. Opin. Plant Biol. 4:392400.

Wen, J. Q., Oono, K., and Imai, R. 2002. Two novel mitogen-activated protein signaling components, OsMEK1 and OsMAP1 are involved in moderate low-temperature signaling pathway in rice. Plant Physiol. 129:1880-1891.

Xiong, L., and Yang, Y. 2003. Disease resistance and abiotic stress tolerance in rice are inversely modulated by an abscisic acid-inducible mitogen-activated protein kinase. Plant Cell 15:745-759.

Xiong, L., Lee, M.-W., Qi, M., and Yang, Y. 2001. Identification of defense-related rice genes by suppression subtractive hybridization and differential screening. Mol. Plant-Microbe Interact. 14:685-692.

Yang, K.Y., Liu, Y., and Zhang, S. 2001. Activation of a mitogen-activated protein kinase pathway is involved in disease resistance in tobacco. Proc. Natl. Acad. Sci. U.S.A. 98:741-746.

Yang, Y, Shah, J., and Klessig, D. F. 1997. Signal perception and transduction in plant defense response. Genes Dev. 11:1621-1639.

Yuan, Q., Ouyang, S., Liu, J., Suh, B., Cheung, F., Sultana, R., Lee, D., Quackenbush, J., and Buell, C. R. 2003. The TIGR rice genome annotation resource: Annotating the rice genome and creating resources for plant biologist. Nucleic Acids Res. 31:229-233.

Zhang, S., and Klessig, D. F. 1997. Salicylic acid activates a 48-kDa MAP kinase in tobacco. Plant Cell 9:809-824.

Zhang, S., and Klessig, D. F. 1998. Resistance gene $N$-mediated de novo synthesis and activation of a tobacco mitogen-activated protein kinase by tobacco mosaic virus infection. Proc. Natl. Acad. Sci. U.S.A. 95:7433-7438.

Zhang, S., and Klessig, D. F. 2001. MAPK cascades in plant defense signaling. Trends Plant Sci. 6:520-527.

\section{AUTHOR-RECOMMENDED INTERNET RESOURCES}

The Biology Workbench: workbench.sdsc.edu

The Institute for Genomic Research (TIGR) website: www.tigr.org

TIGR Rice Genome Annotation website: www.tigr.org/tdb/e2k1/osa1/pseudomolecules/info.shtml 